\title{
Decreased overall mortality rate with Chinese herbal medicine usage in patients with decompensated liver cirrhosis in Taiwan
}

Fuu-Jen Tsai ${ }^{1,2,3+}$, Pei-Yuu Yang ${ }^{4+}$, Chao-Jung Chen ${ }^{2,5}$, Ju-Pi Li1 ${ }^{1,6}$, Te-Mao Li ${ }^{1}$, Jian-Shiun Chiou' ${ }^{7}$, Chi-Fung Cheng ${ }^{2,7}$, Po-Heng Chuang ${ }^{8}$, Ting-Hsu Lin², Chiu-Chu Liao², Shao-Mei Huang ${ }^{2}$, Bo Ban ${ }^{9}$ Wen-Miin Liang ${ }^{7 *}$ and Ying-Ju Lin ${ }^{1,2^{*}}$

\begin{abstract}
Background: Liver cirrhosis is one of the main causes of the morbidity and mortality in liver diseases. Chinese herbal medicine (CHM) has long been used for the clinical treatment of liver diseases. This study was designed to explore the usage frequency and prescription patterns of CHM for patients with decompensated liver cirrhosis and to evaluate the long-term effects of CHM on overall mortality.

Methods: Two thousand four hundred sixty-seven patients with decompensated liver cirrhosis (ICD-9-CM code: 571.2, 571.5, and 571.6) diagnosed between 2000 and 2009 in Taiwan were identified from the registry for catastrophic illness patients. Of these, 149 CHM users and 298 CHM non-users were matched for age, gender, and Charlson comorbidity index score. The chi-squared test, paired Student's t-test, Cox proportional hazard model, and Kaplan-Meier method were applied for various comparisons between these groups of patients.
\end{abstract}

Results: CHM-treated patients showed a lower overall mortality risk compared with non-treated patients (Multivariable: $p<0.0001$; HR: 0.54, 95\% Cl: 0.42-0.69). The cumulative incidence of overall mortality was lower in the CHM-treated group (stratified log-rank test, $p=0.0002$ ). The strongest CHM co-prescription pattern- Yin-Chen-HaoTang (YCHT) $\rightarrow$ Long-Dan-Xie-Gan-Tang (LDXGT) had the highest support, followed by Zhi-Zi (ZZ) $\rightarrow$ Yin-Chen-WuLing-San (YCWLS) and Bai-Hua-She-She-Cao (BHSSC) $\rightarrow$ Da-Huang (DaH).

Conclusion: CHM, as adjunct therapy, might decrease the risk of overall mortality in patients with decompensated liver cirrhosis. CHM co-prescription patterns and network analysis showed that comprehensive herbal medicines have a protective role against liver fibrosis. Further studies are required to enhance the knowledge of safety and efficacy of CHM in patients with decompensated liver cirrhosis.

Keywords: Decompensated liver cirrhosis, Chinese herbal medicine, Overall mortality, Liver fibrosis

\footnotetext{
*Correspondence: wmliang@mail.cmu.edu.tw; yjlin.kath@gmail.com

${ }^{\dagger}$ Fuu-Jen Tsai and Pei-Yuu Yang contributed equally to this work.

${ }^{7}$ Graduate Institute of Biostatistics, School of Public Health, China Medical

University, No. 91, Hsueh-Shih Road, Taichung, Taiwan

'School of Chinese Medicine, China Medical University, No. 91, Hsueh-Shih

Road, Taichung, Taiwan

Full list of author information is available at the end of the article
}

(c) The Author(s). 2020 Open Access This article is licensed under a Creative Commons Attribution 4.0 International License, which permits use, sharing, adaptation, distribution and reproduction in any medium or format, as long as you give appropriate credit to the original author(s) and the source, provide a link to the Creative Commons licence, and indicate if changes were made. The images or other third party material in this article are included in the article's Creative Commons licence, unless indicated otherwise in a credit line to the material. If material is not included in the article's Creative Commons licence and your intended use is not permitted by statutory regulation or exceeds the permitted use, you will need to obtain permission directly from the copyright holder. To view a copy of this licence, visit http://creativecommons.org/licenses/by/4.0/. The Creative Commons Public Domain Dedication waiver (http://creativecommons.org/publicdomain/zero/1.0/) applies to the data made available in this article, unless otherwise stated in a credit line to the data. 


\section{Background}

Liver cirrhosis is a chronic liver disease with liver scarring (liver fibrosis). It is associated with the development of hepatocellular carcinoma, and is also one of the major causes of morbidity and mortality in liver diseases worldwide [1]. In Taiwan, liver cirrhosis is one of the top ten leading causes of death [2]. Liver cirrhosis is characterized by limited liver function with over accumulation of extracellular matrix proteins and is a wound healing reaction to liver injury caused by alcoholism, hepatitis $\mathrm{B}$ and/or hepatitis $\mathrm{C}$ virus infections, and nonalcoholic steatohepatitis [3].

Clinically, liver cirrhosis may either be compensated or decompensated [4]. Compensated liver cirrhosis is characterized by poor but still relatively preserved liver function, while decompensated liver cirrhosis is considered as the extensive and progressive loss of liver function. Ascites is the most frequent symptom, followed by gastrointestinal bleeding, microbial infection, and hepatic encephalopathy. Following appearance of these characteristics, this disease usually progresses rapidly towards death or requires liver transplantation. Management of liver cirrhosis is often focused on preventing liver-related morbidity and mortality and improving the quality of life. Thus, it is urgent to develop and provide effective therapeutic strategies for these patients.

Traditional Chinese medicine (TCM) is popular as adjunct treatment and has the potential to reduce the morbidity and mortality in liver diseases [5]. Chinese herbal medicine (CHM) belongs to TCM and has been applied as adjunct therapy for several diseases to improve diseaserelated complications and mortality in Taiwan [6-15]. Given that liver cirrhosis is one of the top ten leading causes of death in Taiwan, this study focused on patients with decompensated liver cirrhosis from the registry for catastrophic illness patients in Taiwan. This study was designed to explore the long-term effects of $\mathrm{CHM}$ on these patients with decompensated liver cirrhosis.

\section{Methods}

\section{Data resource}

For this study, data was retrieved from the National Health Insurance Research database (NHIRD; from 1996 to 2012), (http://nhird.nhri.org.tw/) of the National Health Insurance (NHI) program in Taiwan (https://www.nhi. gov.tw/english/). This database is managed by the National Health Research Institute (NHRI) and consists of data from a large longitudinal and retrospective cohort of 1 million people randomly sampled from the total population of 24 million. Information contains medical records including age, sex, symptoms, diagnosis of disease, drug prescription, procedures, record of clinical visits and hospitalizations, inpatient orders, ambulatory care, and sociodemographic factors. The medical records collected from this database were anonymized. The study protocol was approved by the Institutional Review Board of China Medical University Hospital.

\section{Study population}

The International Classification of Diseases, 9th Revision, Clinical Modification (ICD-9-CM) was used for the identification of the study population. We conducted a longitudinal and retrospective cohort study with individuals newly diagnosed with decompensated liver cirrhosis (ICD9-CM code: 571.2, 571.5, and 571.6) between 2000 and 2009 from the registry for catastrophic illness patients (Fig. 1). The first record was considered as the date of diagnosis. The exclusion criteria for this study were (1) patients with less than 14 cumulative days of CHM use within 1 year after diagnosis of decompensated liver cirrhosis; (2) cancer diagnosed before decompensated liver cirrhosis; and (3) individuals who had undergone liver transplantation during the study period. Patients were defined as the CHM users who had more than 14 cumulative days of CHM treatment within the first year of diagnosis of decompensated liver cirrhosis $(n=149$, Fig. 1). Patients were defined as the CHM non-users who did not have any recorded use of $\mathrm{CHM}(n=577)$.

There are two forms of CHM - herbal formula and single herb. The formula contains a combination of at least two single herbs prescribed by experienced TCM doctors according to ancient medical books (Table S1). Most single herbs are derived from plants (Table S1). Only Hai-PiaoXiao (HPX), which is a single herb extracted from bones of Sepia officinalis (Cuttlefish Bone) was factory-made by Good Manufacturing Practice certificated pharmaceutical companies within Taiwan (Supplementary file from Chuang Song Zong Pharmaceutical Co. Ltd. (http://www. csz.com.tw/)). For CHM users, their prescription frequency, usage frequency, person-years, average drug dose (gram/ per day), and average duration of prescription (days) were considered (from the index date to the end of the study) according to each herbal formula and single herb (Table S1). The CHM products were produced by the various pharmaceutical manufacturers in Taiwan (Chuang Song Zong Pharmaceutical Co. Ltd. (http://www.csz.com.tw/), Shang Chang Pharmaceutical Co. Ltd. (http://www.herb.com.tw/ about_en.php), Sun Ten Pharmaceutical Co. Ltd. (http:// www.sunten.com.tw/), Kaiser Pharmaceutical Co. Ltd. (http://www.kpc.com/), and KO DA Pharmaceutical Co. Ltd. (http://www.koda.com.tw/)).

To avoid potential confounding factors, both groups were further matched with propensity score (1:2 matching for age, gender, and Charlson comorbidity index score) (Table 1). There were 149 matched CHM users and $298 \mathrm{CHM}$ non-users. The end of 14 cumulative days of CHM use within 1 year was chosen as the index date. During this study period, these CHM users also used 


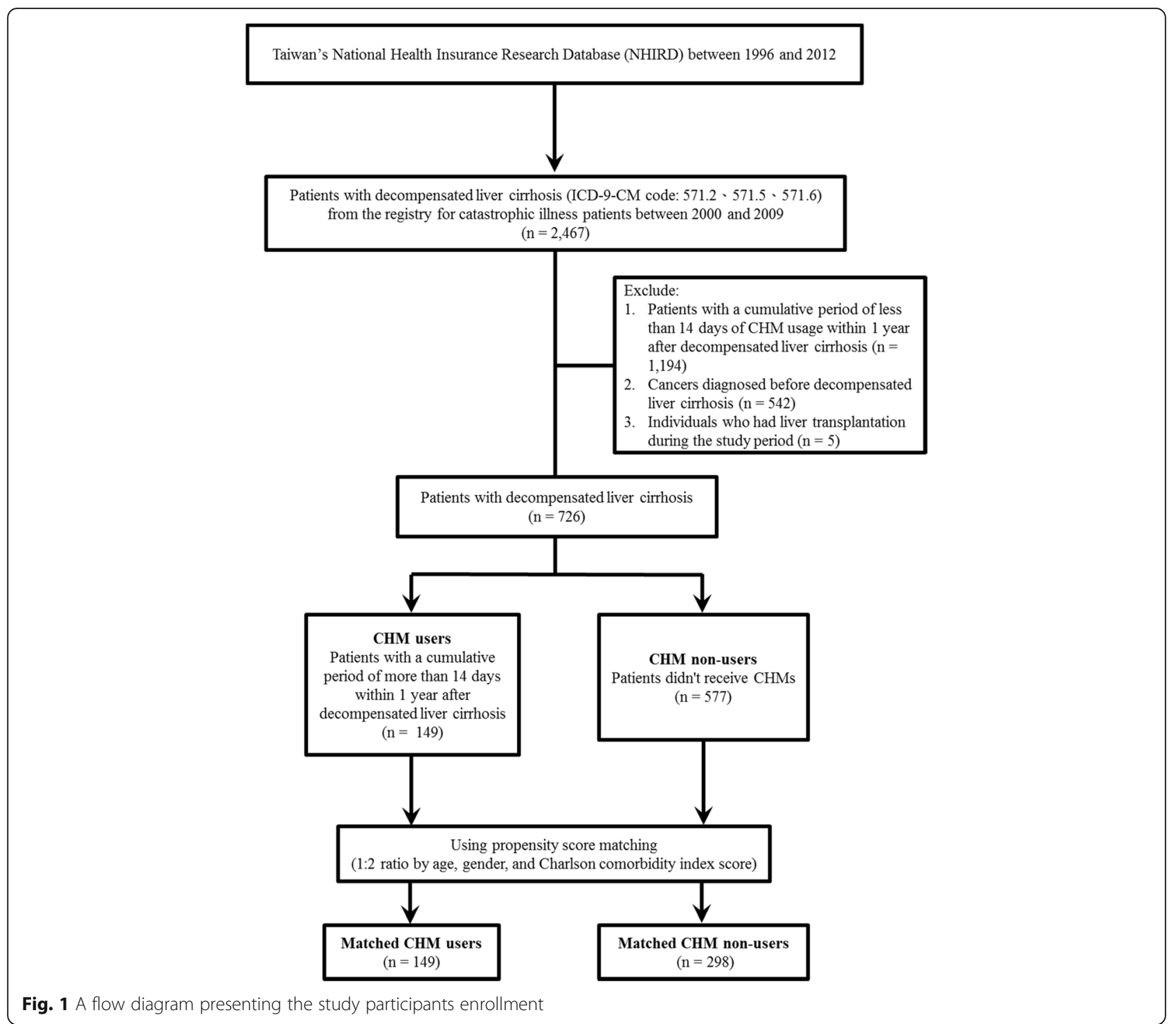

CHM products (Table S5). The study endpoint was a composite of overall mortality, the date of withdrawal from the NHI program, or the date of termination of follow-up (December 31, 2012). Characteristics of CHM and non-CHM using patients with decompensated liver cirrhosis in Taiwan are shown in Table 1. These included age, gender, Charlson comorbidity index score, interferon therapy, anti-viral therapy, income, and urbanization level. Comorbidities were identified before diagnosis of decompensated liver cirrhosis [16, 17]. Income was divided into three subgroups (Table 1 ; < NT20,000, NT20,000-NT30,000, and ミNT30,000). Urbanization levels in Taiwan was divided into three subgroups according to the Taiwan National Health Research Institute publications, with level 1 referring to the lowest level of urbanization and level 3 referring to the highest level.

\section{Statistical analysis}

Categorical data are expressed as absolute number (percentage) and were compared using Chi-squared tests (Table 1). For un-matched and matched subjects, $p$ values for age and Charlson comorbidity index score were calculated using regular Student's t-test and paired Student's t-test (Table 1 and Table S3). Cox proportional hazard models with robust sandwich variance estimator were used to evaluate the hazard ratio (HR) of the risk of overall mortality with adjusted factors (Table 2 and Table S4). Regular Cox proportional hazard models were used to evaluate the hazard ratio (HR) of overall mortality with adjusted factors (Table S2). Adjusted factors included age, gender, Charlson comorbidity index score, $\mathrm{CHM}$ use, and income. The Kaplan-Meier method and the stratified log-rank test were used to assess the 12year cumulative incidence of overall mortality (Fig. 2 
Table 1 Demographic characteristics of decompensated liver cirrhosis patients according to CHM usage in Taiwan

\begin{tabular}{|c|c|c|c|c|c|c|}
\hline \multirow[t]{4}{*}{ Characteristics } & \multicolumn{2}{|l|}{ Total subjects } & \multirow[t]{4}{*}{$\boldsymbol{p}$-value } & \multicolumn{2}{|c|}{ Matched subjects } & \multirow[t]{4}{*}{$\boldsymbol{p}$-value } \\
\hline & CHM users & Non-CHM users & & CHM users & Non-CHM users & \\
\hline & $(\boldsymbol{N}=149)$ & $(\boldsymbol{N}=577)$ & & $(\boldsymbol{N}=149)$ & $(\boldsymbol{N}=298)$ & \\
\hline & N (\%) & N (\%) & & N (\%) & N (\%) & \\
\hline Age (Mean \pm SD) & $53.40 \pm 12.54$ & $54.82 \pm 14.17$ & 0.265 & $53.40 \pm 12.54$ & $54.47 \pm 13.3$ & 0.249 \\
\hline Gender & & & 0.036 & & & 1.000 \\
\hline Male & $106(71.14 \%)$ & $457(79.2 \%)$ & & $106(71.14 \%)$ & $212(71.14 \%)$ & \\
\hline Female & $43(28.86 \%)$ & $120(20.8 \%)$ & & $43(28.86 \%)$ & $86(28.86 \%)$ & \\
\hline Charlson comorbidity index score (Mean \pm SD) & $4.34 \pm 2.12$ & $4.65 \pm 2.41$ & 0.151 & $4.34 \pm 2.12$ & $4.21 \pm 2.39$ & 0.389 \\
\hline Interferon therapy & $2(1.34 \%)$ & $3(0.52 \%)$ & 0.279 & $2(1.34 \%)$ & $3(1.01 \%)$ & 0.750 \\
\hline Anti-virus therapy & $2(1.34 \%)$ & $3(0.52 \%)$ & 0.279 & $2(1.34 \%)$ & $3(1.01 \%)$ & 0.750 \\
\hline Income & & & 0.006 & & & 0.017 \\
\hline$<\mathrm{NT20,000}$ & $81(54.36 \%)$ & $387(67.07 \%)$ & & 81 (54.36\%) & 198 (66.44\%) & \\
\hline NT20,000-NT30,000 & $40(26.85 \%)$ & $128(22.18 \%)$ & & $40(26.85 \%)$ & 69 (23.15\%) & \\
\hline$\geqq N T 30,000$ & $28(18.79 \%)$ & $62(10.75 \%)$ & & $28(18.79 \%)$ & $31(10.4 \%)$ & \\
\hline Urbanization level & & & 0.553 & & & 0.538 \\
\hline 1 & 77 (55.40\%) & $296(53.72 \%)$ & & 77 (55.4\%) & 152 (53.15\%) & \\
\hline 2 & 40 (28.78\%) & $146(26.50 \%)$ & & 40 (28.78\%) & 76 (26.57\%) & \\
\hline 3 & $22(15.83 \%)$ & 109 (19.78\%) & & $22(15.83 \%)$ & $58(20.28 \%)$ & \\
\hline
\end{tabular}

p-values for gender, interferon therapy, anti-virus therapy, income, and urbanization level were calculated with chi-square test For matched subjects, $p$-values for age and Charlson comorbidity index score were calculated using paired Student's t-test CHM Chinese herbal medicine; $N$ number

These comorbidities were identified before decompensated liver cirrhosis

Propensity score matching was performed for CHM and non-CHM users in 1:2 ratio for age, sex, and Charlson comorbidity index score Urbanization level: 1 indicates the lowest level of urbanization and 3 is the highest level

and Fig. S3). The Kaplan-Meier method and the logrank test were used to assess the 12-year cumulative incidence of overall mortality (Fig. S1). Parameters for counting the cumulative incidence of overall mortality are shown for CHM and CHM non-users (Table S7 and Table S8). Interval (Lower; Upper) refers to the follow-up time; for example: lower $=0$; upper $=1$ means the interval between 0 and 1 year. Effective sample size (n) refers to the total sample number in the CHM or CHM non-users. $\mathrm{n}=\mathrm{N}-1 / 2$ $(\mathrm{NC})$; where number of censored (NC) means the number of withdrawal or loss of follow-up during the interval in the two groups. Conditional probability of failure was calculated as $(q)=N F / n$. Survival was calculated as $(\mathrm{p})=\Pi p=\Pi(1-\mathrm{q})$. Overall mortality was calculated as 1-Survival. Co-prescription pairs of CHM products were shown by using association rules [18] (the "arules_1.6" package of R software (version 3.4.3); Table 3). Cytoscape network analysis (http:// manual.cytoscape.org/en/stable/Network_Analyzer.

html) was used to investigate the CHM network (Fig. 3). All $p$-values less than 0.05 were considered statistically significant. Statistical analyses were performed using SAS software (version 9.4; SAS Institute, Cary, NC, USA).

\section{Results}

The flow chart for the identification of patients with decompensated liver cirrhosis is presented in Fig. 1. A total of 2467 patients with decompensated liver cirrhosis were identified for the period between the years 2000 and 2009 from the registry for patients with catastrophic illness in Taiwan. After exclusion of patients based on the exclusion criteria, a total of 726 patients with decompensated liver cirrhosis were included in the analysis. Of these, 149 were in the CHM users' group, while 577 were in the CHM non-users' group. Differences were found in gender and income between these 2 groups $(p<0.05$; Table 1$)$, with more females and higher income in the CHM group. After matching for age, gender, and Charlson comorbidity index score, 149 and 298 patients were included in the $\mathrm{CHM}$ user and $\mathrm{CHM}$ non-user groups, respectively (Fig. 1 and Table 1). The only difference observed between these two matched groups was higher income in the CHM group $(p<0.05$; Table 1$)$.

As shown in Table 2, CHM users had a lower overall mortality risk compared with $\mathrm{CHM}$ non-users (Crude: $p<0.0001$; HR: 0.54, 95\% CI: 0.43-0.68). After adjusting for age, gender, Charlson comorbidity index score, and income; CHM users still had a lower overall mortality risk than those $\mathrm{CHM}$ non-users (Multivariable: $p<$ 
Table 2 Hazard ratios (95\% Cl) for overall mortality of decompensated liver cirrhosis patients

\begin{tabular}{|c|c|c|c|c|c|c|c|c|}
\hline & \multirow{2}{*}{$\begin{array}{l}\text { Number of } \\
\text { death }(\boldsymbol{n}=313) \\
N(\%)\end{array}$} & \multirow{2}{*}{$\begin{array}{l}\text { Total }(\boldsymbol{n}= \\
447) \\
\mathrm{N}\end{array}$} & \multicolumn{3}{|l|}{ Crude } & \multicolumn{3}{|c|}{ Multivariable } \\
\hline & & & $\begin{array}{l}\text { Hazard } \\
\text { ratio }\end{array}$ & $95 \% \mathrm{Cl}$ & $\boldsymbol{p}$-value & $\begin{array}{l}\text { Hazard } \\
\text { ratio }\end{array}$ & $95 \% \mathrm{Cl}$ & $\boldsymbol{p}$-value \\
\hline \multicolumn{9}{|l|}{ CHM use (vs. non-CHM use) } \\
\hline No & $225(75.50 \%)$ & 298 & Ref. & Ref. & Ref. & Ref. & Ref. & Ref. \\
\hline Yes & $88(59.06 \%)$ & 149 & 0.54 & $(0.43-0.68)$ & $\begin{array}{l}< \\
0.0001\end{array}$ & 0.54 & $\begin{array}{l}(0.42- \\
0.69)\end{array}$ & $\begin{array}{l}< \\
0.0001\end{array}$ \\
\hline Age (per year) & ND & ND & 1.02 & $(1.01-1.03)$ & 0.0007 & 1.01 & $\begin{array}{l}(1.00- \\
1.02)\end{array}$ & 0.0119 \\
\hline \multicolumn{9}{|l|}{ Gender } \\
\hline Male & $216(67.92 \%)$ & 318 & Ref. & Ref. & Ref. & Ref. & Ref. & Ref. \\
\hline Female & 97 (75.19\%) & 129 & 1.32 & $(1.05-1.68)$ & 0.0196 & 1.03 & $\begin{array}{l}(0.80- \\
1.33)\end{array}$ & 0.8018 \\
\hline $\begin{array}{l}\text { Charlson comorbidity index score (per } \\
\text { score) }\end{array}$ & ND & ND & 1.08 & $(1.03-1.13)$ & 0.0023 & 1.07 & $\begin{array}{l}(1.01- \\
1.13)\end{array}$ & 0.0210 \\
\hline \multicolumn{9}{|l|}{ Income } \\
\hline$<$ NT20,000 & $220(78.85 \%)$ & 279 & Ref. & Ref. & Ref. & Ref. & Ref. & Ref. \\
\hline NT20,000-NT30,000 & $58(53.21 \%)$ & 109 & 0.53 & $(0.39-0.72)$ & $\begin{array}{l}< \\
0.0001\end{array}$ & 0.54 & $\begin{array}{l}(0.39- \\
0.74)\end{array}$ & 0.0001 \\
\hline$\geqq N T 30,000$ & 35 (59.32\%) & 59 & 0.58 & $(0.41-0.82)$ & 0.0024 & 0.64 & $\begin{array}{l}(0.44- \\
0.93)\end{array}$ & 0.0203 \\
\hline
\end{tabular}

CHM Chinese herbal medicine; $H R$ hazard ratio; $95 \%$ Cl 95\% confidence interval; Ref reference; $N D$ not determined

Adjusted factors included age, gender, Charlson comorbidity index score, CHM use, and income

Cox proportional hazard models with robust sandwich variance estimator were applied in this analysis

0.0001; HR: 0.54, 95\% CI: 0.42-0.69). Parameters for counting the cumulative incidence of overall mortality for CHM users and CHM non-users are shown in Table S7 and Table S8. Kaplan-Meier survival curves showed that the cumulative incidence of overall mortality in $\mathrm{CHM}$ users was lower than that in $\mathrm{CHM}$ non-users (stratified log-rank test, $p=0.0002$; Fig. 2). The average survival time for CHM users was 4.232 years, while the average survival time for CHM non-users was 2.569 years (Table S6).

The commonly used Chinese herbal formulas and single herbs and their compositions used for the treatment

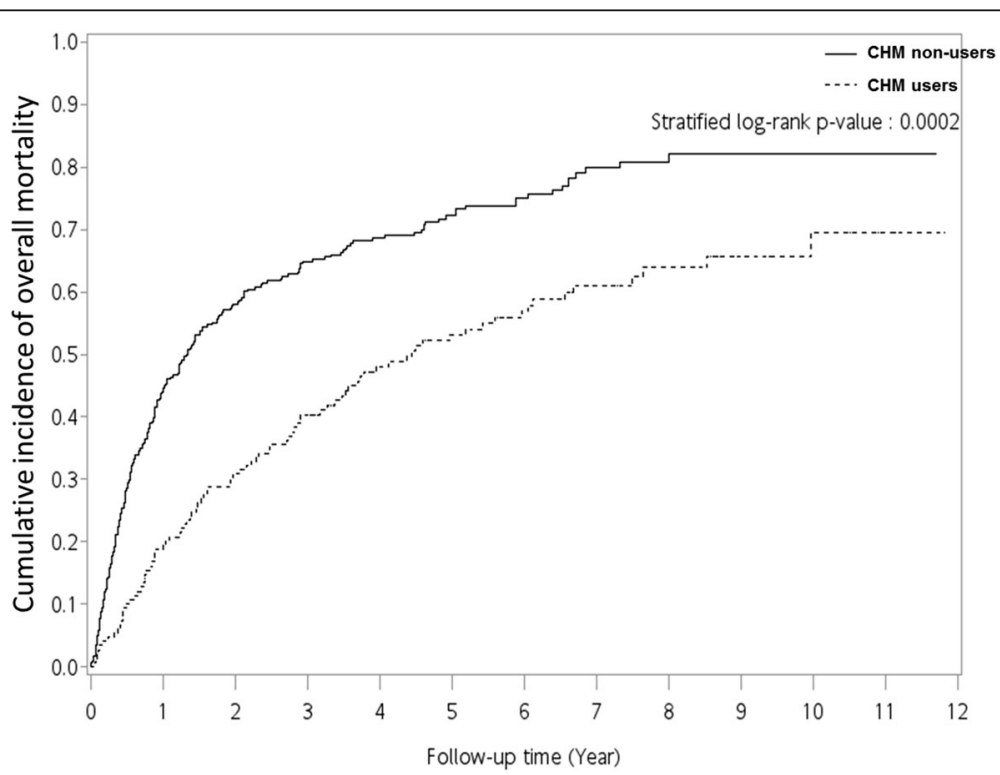

Fig. 2 The cumulative incidence of overall mortality in decompensated liver cirrhosis patients based on usage of Chinese herbal medicine (CHM) 
Table 3 Ten most commonly used pairs of CHM products for decompensated liver cirrhosis patients in Taiwan

\begin{tabular}{|c|c|c|c|c|c|c|c|c|}
\hline 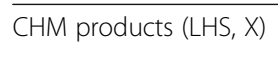 & $\begin{array}{l}\text { Chinese } \\
\text { name }\end{array}$ & & CHM products (RHS, Y) & $\begin{array}{l}\text { Chinese } \\
\text { name }\end{array}$ & $\begin{array}{l}\text { Frequency of prescriptions of } X \\
\text { and } Y \text { products }\end{array}$ & $\begin{array}{l}\text { Support } \\
(X)(\%)\end{array}$ & $\begin{array}{l}\text { Confidence } \\
(X \rightarrow Y)(\%)\end{array}$ & Lift \\
\hline $\begin{array}{l}\text { Yin-Chen-Hao-Tang } \\
\text { (YCHT) }\end{array}$ & 茵陳蒿湯 & $\rightarrow$ & $\begin{array}{l}\text { Long-Dan-Xie-Gan- } \\
\text { Tang (LDXGT) }\end{array}$ & $\begin{array}{l}\text { 龍膽瀉肝 } \\
\text { 湯 }\end{array}$ & 144 & 3.81 & 43.24 & 4.83 \\
\hline Zhi-Zi (ZZ) & 栃子 & $\rightarrow$ & $\begin{array}{l}\text { Yin-Chen-Wu-Ling-San } \\
\text { (YCWLS) }\end{array}$ & $\begin{array}{l}\text { 茵陳五苓 } \\
\text { 散 }\end{array}$ & 135 & 3.57 & 68.53 & 4.80 \\
\hline $\begin{array}{l}\text { Bai-Hua-She-She-Cao } \\
\text { (BHSSC) }\end{array}$ & $\begin{array}{l}\text { 白花蛇舌 } \\
\text { 草 }\end{array}$ & $\rightarrow$ & Da-Huang (DaH) & 大黃 & 128 & 3.38 & 63.05 & 6.65 \\
\hline Dan-Shen (DanS) & 丹參 & $\rightarrow$ & $\begin{array}{l}\text { Jia-Wei-Xiao-Yao-San } \\
\text { (JWXYS) }\end{array}$ & $\begin{array}{l}\text { 加味逍遙 } \\
\text { 散 }\end{array}$ & 124 & 3.28 & 28.12 & 2.18 \\
\hline Da-Huang (DaH) & 大黄 & $\rightarrow$ & $\begin{array}{l}\text { Yin-Chen-Wu-Ling-San } \\
\text { (YCWLS) }\end{array}$ & $\begin{array}{l}\text { 茵陳五苓 } \\
\text { 散 }\end{array}$ & 114 & 3.01 & 31.75 & 2.23 \\
\hline Zhi-Zi (ZZ) & 柧子 & $\rightarrow$ & Da-Huang (DaH) & 大黃 & 112 & 2.96 & 56.85 & 5.99 \\
\hline $\begin{array}{l}\text { Long-Dan-Xie-Gan- } \\
\text { Tang (LDXGT) }\end{array}$ & $\begin{array}{l}\text { 龍膽瀉肝 } \\
\text { 湯 }\end{array}$ & $\rightarrow$ & $\begin{array}{l}\text { Jia-Wei-Xiao-Yao-San } \\
\text { (JWXYS) }\end{array}$ & $\begin{array}{l}\text { 加味逍遙 } \\
\text { 散 }\end{array}$ & 103 & 2.72 & 30.38 & 2.36 \\
\hline $\begin{array}{l}\text { Yin-Chen-Hao-Tang } \\
\text { (YCHT) }\end{array}$ & 茵陳蒿湯 & $\rightarrow$ & $\begin{array}{l}\text { Jia-Wei-Xiao-Yao-San } \\
\text { (JWXYS) }\end{array}$ & $\begin{array}{l}\text { 加味逍遙 } \\
\text { 散 }\end{array}$ & 100 & 2.64 & 30.03 & 2.33 \\
\hline $\begin{array}{l}\text { Ban-Xia-Xie-Xin-Tang } \\
\text { (BXXXT) }\end{array}$ & $\begin{array}{l}\text { 半夏瀉心 } \\
\text { 湯 }\end{array}$ & $\rightarrow$ & $\begin{array}{l}\text { Yin-Chen-Hao-Tang } \\
\text { (YCHT) }\end{array}$ & 茵陳蒿湯 & 99 & 2.62 & 42.86 & 4.87 \\
\hline San-Qi (SanQ) & 三七 & $\rightarrow$ & $\begin{array}{l}\text { Jia-Wei-Xiao-Yao-San } \\
\text { (JWXYS) }\end{array}$ & $\begin{array}{l}\text { 加味逍遙 } \\
\text { 散 }\end{array}$ & 96 & 2.54 & 46.83 & 3.64 \\
\hline Zhi-Zi (ZZ) & 栃子 & $\rightarrow$ & $\begin{array}{l}\text { Bai-Hua-She-She-Cao } \\
\text { (BHSSC) }\end{array}$ & $\begin{array}{l}\text { 白花蛇舌 } \\
\text { 草 }\end{array}$ & 79 & 2.09 & 40.10 & 7.48 \\
\hline $\begin{array}{l}\text { Bai-Hua-She-She-Cao } \\
\text { (BHSSC) }\end{array}$ & $\begin{array}{l}\text { 白花蛇舌 } \\
\text { 草 }\end{array}$ & $\rightarrow$ & $\begin{array}{l}\text { Yin-Chen-Wu-Ling-San } \\
\text { (YCWLS) }\end{array}$ & $\begin{array}{l}\text { 茵陳五苓 } \\
\text { 散 }\end{array}$ & 76 & 2.01 & 37.44 & 2.62 \\
\hline Da-Huang (DaH) & 大黃 & $\rightarrow$ & Dan-Shen (DanS) & 丹參 & 63 & 1.66 & 17.55 & 1.51 \\
\hline San-Qi (SanQ) & 三七 & $\rightarrow$ & Dan-Shen (DanS) & 丹參 & 65 & 1.72 & 31.71 & 2.72 \\
\hline San-Qi (SanQ) & 三七 & $\rightarrow$ & $\begin{array}{l}\text { Long-Dan-Xie-Gan- } \\
\text { Tang (LDXGT) }\end{array}$ & $\begin{array}{l}\text { 龍膽瀉肝 } \\
\text { 湯 }\end{array}$ & 65 & 1.72 & 31.71 & 3.54 \\
\hline San-Qi (SanQ) & 三七 & $\rightarrow$ & $\begin{array}{l}\text { Ban-Xia-Xie-Xin-Tang } \\
(\text { BXXXT) }\end{array}$ & $\begin{array}{l}\text { 半夏瀉心 } \\
\text { 湯 }\end{array}$ & 52 & 1.37 & 25.37 & 4.16 \\
\hline San-Qi (SanQ) & 三七 & $\rightarrow$ & $\begin{array}{l}\text { Yin-Chen-Hao-Tang } \\
\text { (YCHT) }\end{array}$ & 茵陳蒿湯 & 63 & 1.66 & 30.73 & 3.49 \\
\hline $\begin{array}{l}\text { Ban-Xia-Xie-Xin-Tang } \\
\text { (BXXXT) }\end{array}$ & $\begin{array}{l}\text { 半夏瀉心 } \\
\text { 湯 }\end{array}$ & $\rightarrow$ & $\begin{array}{l}\text { Jia-Wei-Xiao-Yao-San } \\
\text { (JWXYS) }\end{array}$ & $\begin{array}{l}\text { 加味逍遙 } \\
\text { 散 }\end{array}$ & 83 & 2.19 & 35.93 & 2.79 \\
\hline $\begin{array}{l}\text { Ban-Xia-Xie-Xin-Tang } \\
(\text { BXXXT) }\end{array}$ & $\begin{array}{l}\text { 半夏瀉心 } \\
\text { 湯 }\end{array}$ & $\rightarrow$ & $\begin{array}{l}\text { Long-Dan-Xie-Gan- } \\
\text { Tang (LDXGT) }\end{array}$ & $\begin{array}{l}\text { 龍膽瀉肝 } \\
\text { 湯 }\end{array}$ & 94 & 2.48 & 40.69 & 4.54 \\
\hline
\end{tabular}

CHM Chinese herbal medicine; LHS left-hand-side; RHS right-hand-side

Support $(X)(\%)=$ Frequency of prescriptions of $X$ and $Y$ products/total prescriptions $\times 100 \%$

Confidence $(X \rightarrow Y)(\%)=$ Frequency of prescriptions of $X$ and $Y$ products / Frequency of prescriptions of $X$ product $\times 100 \%$

$\mathrm{P}(\mathrm{Y})(\%)=$ Frequency of prescriptions of $\mathrm{Y}$ product $/$ total prescriptions $\times 100 \%$

Lift $=$ Confidence $(X \rightarrow Y)(\%) / P(Y)(\%)$

of patients with decompensated liver cirrhosis are listed in Table S1. Results of the association rules and network analysis, i.e., the support (\%), confidence (\%), and lift of the association rules of these most commonly used coprescription pairs are shown in Table 3 and Fig. 3. The strongest CHM co-prescription pattern (Yin-Chen-HaoTang $\quad(\mathrm{YCHT}) \rightarrow$ Long-Dan-Xie-Gan-Tang (LDXGT); support: $3.81 \%$, confidence: $43.24 \%$, lift: 4.83$)$ showed the highest value of support data, which suggests that this co-prescription pattern had the most significant association for the treatment of decompensated liver cirrhosis. This was followed by Zhi-Zi (ZZ) $\rightarrow$ Yin-Chen-
Wu-Ling-San (YCWLS) (support: 3.57\%, confidence: 68.53\%, lift: 4.80) and Bai-Hua-She-She-Cao (BHSSC) $\rightarrow$ Da-Huang (DaH) (support: $3.38 \%$, confidence: $63.05 \%$, lift: 6.65).

To explore the CHM network, the CHM combinations, co-prescription patterns and constituted networks were identified and drawn (Fig. 3). There was one main CHM cluster with Yin-Chen-Hao-Tang (YCHT), LongDan-Xie-Gan-Tang (LDXGT), Ban-Xia-Xie-Xin-Tang (BXXXT), Jia-Wei-Xiao-Yao-San (JWXYS), Dan-Shen (DanS), and San-Qi (SanQ). The second main CHM cluster was Yin-Chen-Wu-Ling-San (YCWLS), Bai-Hua- 


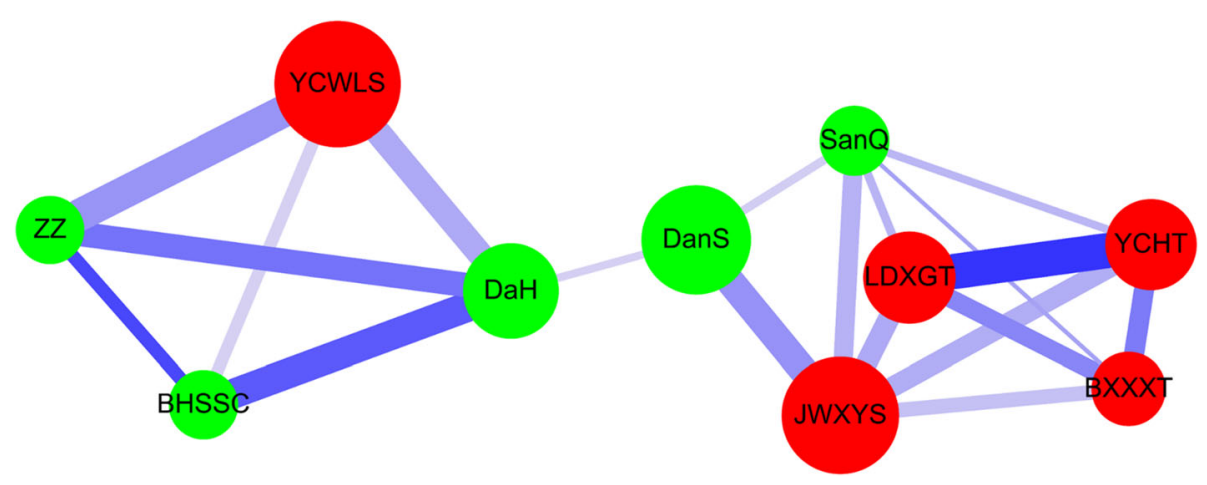

Fig. 3 The CHM network in patients with decompensated liver cirrhosis. The lines connecting CHMs represent the support value, where thicker lines represent higher support values, and darker lines represent higher lift values. The thicker and darker the connecting line, the more important the connection between CHMs. The size of the circle represents the frequency of prescription of individual CHMs i.e., larger circles represent higher prescription frequencies. Red circles represent herbal formulas and green circles represent single herbs

She-She-Cao (BHSSC), Da-Huang (DaH), and Zhi-Zi (ZZ). We observed that the use of CHM as adjunct therapy may reduce the risk of overall mortality in decompensated liver cirrhosis patients. These CHM co-prescription patterns may exhibit anti-fibrotic effects in the liver and may show protective effects against overall mortality.

\section{Discussion}

This study has shown that CHM treatment is associated with a lower overall mortality risk in patients with decompensated liver cirrhosis. Among these patients, the strongest CHM co-prescription pattern (YCHT $\rightarrow$ LDXGT) had the highest value of support data, followed by ZZ $\rightarrow$ YCWLS and BHSSC $\rightarrow \mathrm{DaH}$. The study was aimed at exploring the potential effects of these herbs on liver fibrosis and the subsequent overall mortality in these patients.

Liver cirrhosis is a late stage of scarring in the liver characterized by a complex consisting of different kinds of extracellular matrix (ECM) proteins such as type I, III, and IV collagen proteins, elastic fibers, fibronectin, laminin, and proteoglycans [19].. Alcoholism, hepatitis B and/or hepatitis $\mathrm{C}$ virus infections, and nonalcoholic steatohepatitis may induce a wound healing response (fibrogenesis), and extra synthesis of ECM with an overexpression of tissue inhibitors of matrix metalloproteinases (TIMPs) [20]. Currently, there are several kinds of anti-fibrotic drug candidates that have shown anti-fibrotic activities in vitro, in animal studies, and/ or in clinical patients $[21,22]$. These include cytokine antagonists, phosphodiesterase inhibitors, matrix metalloproteinase (MMP) inducers, prostanoids, vasoactive modulators, histone deacetylase inhibitors, peroxisome proliferatoractivated receptor (PPAR)-alpha agonists, PPAR-gamma agonists, plant-derived drugs, and farnesoid-X-receptor agonists $[4,21]$. The drug candidates can be used in combination, either for long-term or for short-term; however, the long-term safety of the combination of these anti-fibrotic drug candidates for liver cirrhosis patients remains to be elucidated.

The results of this study suggest that CHM may have protective effect in these patients with decompensated liver cirrhosis. Similar results were also observed in the total subjects (before matching) (Table 1, Table S2, and Fig. S1). These results suggested that CHM treatment was associated with a lower overall mortality risk in decompensated liver cirrhosis patients in both of the total and matched subjects. Furthermore, CHM users had a lower overall mortality risk than CHM non-users from both of the database of the registry for catastrophic illness patients and the database of outpatient and inpatient, suggesting that there may not be a selection bias in our study (Table S3, Table S4, Fig, S2, and Fig. S3). Truly, there is increasing evidence that CHM has long been used for the clinical treatment of liver diseases in Taiwan [15, 23-26]. Our results provide a motivation to investigate these CHM for pharmacological effects in decompensated liver cirrhosis. Among the co-prescription patterns determined by using the association rule mining for decompensated liver cirrhosis patients, the strongest CHM co-prescription pattern YCHT $\rightarrow$ LDXGT resulted in the highest support, followed by ZZ $\rightarrow$ YCWLS and $\mathrm{BHSSC} \rightarrow \mathrm{DaH}$. These three stronger coprescription patterns seem to be independent of each other according to the CHM network analysis. Based on the theory of TCM, YCHT and LDXGT are strong CHM prescriptions used to eliminate heat and dampness from the human body and to improve liver regulation and jaundice remission. Indeed, they have been used in treating liver diseases in ancient China and are still used to treat chronic hepatitis in Taiwan [27, 28]. YCHT comprises three single herbs - Yin-Chen-Hao (YCH; Artemisia capillaris Thunb.), ZZ (Gardenia jasminoides J.Ellis), and DaH (Rheum palmatum L.). YCWLS is a herbal formula derived from YCHT and is frequently 
prescribed for chronic hepatitis and liver cirrhosis in Taiwan $[15,27]$. YCHT has been shown to protect the liver from fibrosis and oxidative stress in rat or mouse models [29-34]. Among YCHT, herbal extracts from YCH; Artemisia capillaris Thunb. and DaH; Rheum palmatum $L$. have shown anti-fibrotic effects in rat livers $[35,36]$. Chlorogenic acid and umbelliferone are the natural compounds of $\mathrm{YCH}$ and protect from liver fibrosis [37-39]. Geniposide, genipin, and crocin are the natural compounds of $\mathrm{ZZ}$ and also exhibit anti-fibrotic activity in the liver [40-42]. Emodin and rhein are the natural compounds of $\mathrm{DaH}$ and alleviate liver fibrosis [43-45]. LDXGT is composed of ten single herbs [27]. Three natural compounds swertiamarin, geniposide, and baicalin have been identified in LDXGT and have shown anti-fibrotic activity in the liver [40, 46-48]. BHSSC; Oldenlandia diffusa (Willd.) Roxb. is well-known for the treatment of hepatitis and liver cancer $[49,50]$. Oleanolic acid and ursolic acid are two natural compounds of BHSSC [51]. A derivative of oleanolic acid has shown antifibrotic effects in rat livers [52]. Ursolic acid has shown to exhibit anti-fibrotic effects in the liver of mice and rats [53-56].

Our co-prescription patterns and network analysis have shown that YCHT, YCWLS, LDXGT, and BHSSC exhibited anti-fibrotic activity in the liver and may attenuate overall mortality in decompensated liver cirrhosis. This study has shown that adjunct therapy using CHM may be useful for attenuating overall mortality in patients with decompensated liver cirrhosis.

The limitations of this study include the lack of information about patient education, lifestyle-diet, behavior, occupation, and blood biochemical analysis of liver function and other clinical diagnostic data. This study provides co-prescription patterns with potential protective effects in these patients, which can show a direction for future investigations regarding the safety and efficacy of these agents against liver fibrosis, and possible drug interactions. Further, prospective studies or ad hoc designed clinical trials are necessary in this regard. Functional investigation of $\mathrm{CHM}$ and related natural compounds protective effects against liver fibrosis are also necessary.

\section{Conclusions}

CHM usage exhibited a lower hazard ratio for the risk of overall mortality. The strongest CHM co-prescription pattern YCHT $\rightarrow$ LDXGT caused the highest support, followed by ZZ $\rightarrow$ YCWLS and BHSSC $\rightarrow \mathrm{DaH}$. The use of CHM may reduce the risk of overall mortality in patients with decompensated liver cirrhosis; however, further studies are required to optimize the safety and efficacy.

\section{Supplementary information}

Supplementary information accompanies this paper at https://doi.org/10. 1186/s12906-020-03010-6.

\begin{abstract}
Additional file 1 Figure $\mathbf{S 1}$. The cumulative incidence of overall mortality in patients with decompensated liver cirrhosis based on Chinese herbal medicine (CHM) usage (before matching). Figure S2. A flow diagram presenting the study participants enrollment (from the database of outpatient and inpatient). Figure S3. The cumulative incidence of overall mortality in patients with decompensated liver cirrhosis based on Chinese herbal medicine (CHM) usage (from the database of outpatient and inpatient). Table S1 Composition of the most commonly used herbal formulas and single herbs in patients with decompensated liver cirrhosis in Taiwan. Table S2 Hazard ratios (95\% Cl) for overall mortality of patients with decompensated liver cirrhosis (before matching). Table S3 Demographic characteristics of patients with decompensated liver cirrhosis according to CHM usage in Taiwan (from the database of outpatient and inpatient). Table S4 Hazard ratios (95\% Cl) for overall mortality of patients with decompensated liver cirrhosis (from the database of outpatient and inpatient). Table S5. Distribution of the cumulative period of CHM treatment of CHM users of patients with decompensated liver cirrhosis in this study in Taiwan (during study period after the index date). Table S6. Average survival time of patients with decompensated liver cirrhosis between CHM and CHM non-users. Table S7. Parameters for counting the cumulative incidence of overall mortality at Fig. 2 for CHM non-users. Table S8. Parameters for counting the cumulative incidence of overall mortality at Fig. 2 for $\mathrm{CHM}$ users.
\end{abstract}

\section{Abbreviations}

HCC: Hepatocellular carcinoma; CAM: Complementary and alternative medicine; CHM: Chinese herbal medicine; NHIRD: National Health Insurance Research database; HR: Hazard ratio; ICD-9-CM: international Classification of Disease, 9th Revision, Clinical Modification; YCHT: Yin-Chen-Hao-Tang; LDXGT: Long-Dan-Xie-Gan-Tang; ZZ: Zhi-Zi; YCWLS: Yin-Chen-Wu-Ling-San; BHSSC: Bai-Hua-She-She-Cao; DaH: Da-Huang

\section{Acknowledgements}

This study was based, in part, on the data from the National Health Insurance Research Database provided by the Bureau of National Health Insurance, Department of Health and managed by the National Health Research Institutes. The interpretation and conclusions contained herein do not represent those of the National Health Insurance Administration,

Department of Health or National Health Research Institutes. We also thank Dr. Kuan-Teh Jeang and Willy W.L. Hong for their technical help and suggestions.

\section{Authors' contributions}

FJT, JPL, WML, and YJL conceived and designed the experiments. CJC, JSC, CFC, THL, CCL, and SMH performed the experiments. JSC and CFC analyzed the data. PYY, TML, and PHCcontributed reagents/materials/analysis tools. $J P L, P Y Y$, and YJL wrote the manuscript. All authors have read and approved of the final manuscript.

\section{Funding}

This work was supported by the China Medical University [grant numbers CMU108-MF-32, CMU108-S-15, and CMU108-S-17], China Medical University Hospital [grant numbers DMR-109-145, DMR-109-188, and DMR-109-192], and the Ministry of Science and Technology, Taiwan [grand numbers MOST 106-2320-B-039 -017 -MY3, MOST 108-2314-B-039-044-MY3, and MOST 1092320-B-039-035-MY3]. These funding resources had no role in the design of the study and collection, analysis, and interpretation of data and in writing the manuscript.

\section{Availability of data and materials}

The data that support the findings of this study are available from the National Health Research Institute (NHRI), but restrictions apply to the availability of these data, which were used under license for the current study, and so are not publicly available. 


\section{Ethics approval and consent to participate}

The study protocol was approved by the Institutional Review Board of China Medical University Hospital. The medical records collected from this database were anonymized. Therefore, there is no need for consent to participate.

\section{Consent for publication}

Not applicable.

\section{Competing interests}

The authors declare that they have no competing interests.

\section{Author details}

${ }^{1}$ School of Chinese Medicine, China Medical University, No. 91, Hsueh-Shih Road, Taichung, Taiwan. ${ }^{2}$ Genetic Center, Proteomics Core Laboratory, Department of Medical Research, China Medical University Hospital, Taichung, Taiwan. ${ }^{3}$ Asia University, Taichung, Taiwan. ${ }^{4}$ Department of Traditional Chinese Medicine, Taipei Medical University Hospital, Taipei, Taiwan. ${ }^{5}$ Graduate Institute of Integrated Medicine, China Medical University, Taichung, Taiwan. ${ }^{6}$ Rheumatism Research Center, China Medical University Hospital, Taichung, Taiwan. ${ }^{7}$ Graduate Institute of Biostatistics, School of Public Health, China Medical University, No. 91, Hsueh-Shih Road, Taichung, Taiwan. ${ }^{8}$ Division of Hepato-gastroenterology, Department of Internal Medicine, China Medical University Hospital, Taichung, Taiwan. ${ }^{9}$ Chinese Research Center for Behavior Medicine in Growth and Development, 89 Guhuai Road, Jining, Shandong, China.

\section{Received: 15 April 2019 Accepted: 2 July 2020}

\section{Published online: 14 July 2020}

\section{References}

1. Sharma S, Khalili K, Nguyen GC. Non-invasive diagnosis of advanced fibrosis and cirrhosis. World J Gastroenterol. 2014;20(45):16820-30.

2. Hsiao AJ, Chen LH, Lu TH. Ten leading causes of death in Taiwan: a comparison of two grouping lists. J Formos Med Assoc. 2015;114(8):679-80.

3. Sebastiani G, Gkouvatsos K, Pantopoulos K. Chronic hepatitis C and liver fibrosis. World J Gastroenterol. 2014;20(32):11033-53.

4. Schuppan D, Afdhal NH. Liver cirrhosis. Lancet. 2008;371(9615):838-51.

5. Zhang L, Schuppan D. Traditional Chinese medicine (TCM) for fibrotic liver disease: hope and hype. J Hepatol. 2014;61(1):166-8.

6. Lin YJ, Ho TJ, Yeh YC, Cheng CF, Shiao YT, Wang CB, Chien WK, Chen JH, Liu $X$, Tsang $H$, et al. Chinese herbal medicine treatment improves the overall survival rate of individuals with hypertension among type 2 diabetes patients and modulates in vitro smooth muscle cell contractility. PLoS One. 2015:10(12):e0145109.

7. Lee AL, Chen BC, Mou CH, Sun MF, Yen HR. Association of Traditional Chinese Medicine Therapy and the risk of vascular complications in patients with type II diabetes mellitus: a Nationwide, retrospective, Taiwaneseregistry, cohort study. Medicine (Baltimore). 2016;95(3):e2536.

8. Chen $\mathrm{YL}$, Lee $\mathrm{CY}$, Huang $\mathrm{KH}$, Kuan $\mathrm{YH}$, Chen M. Prescription patterns of Chinese herbal products for patients with sleep disorder and major depressive disorder in Taiwan. J Ethnopharmacol. 2015;171:307-16.

9. Chu SM, Shih WT, Yang YH, Chen PC, Chu YH. Use of traditional Chinese medicine in patients with hyperlipidemia: a population-based study in Taiwan. J Ethnopharmacol. 2015;168:129-35.

10. Hsu PC, Tsai YT, Lai JN, Wu CT, Lin SK, Huang CY. Integrating traditional Chinese medicine healthcare into diabetes care by reducing the risk of developing kidney failure among type 2 diabetic patients: a populationbased case control study. J Ethnopharmacol. 2014;156:358-64.

11. Chen HY, Lin YH, Thien PF, Chang SC, Chen YC, Lo SS, Yang SH, Chen JL. Identifying core herbal treatments for children with asthma: implication from a chinese herbal medicine database in Taiwan. Evid Based Complement Alternat Med. 2013;2013:125943.

12. Chao TH, Fu PK, Chang CH, Chang SN, Chiahung Mao F, Lin CH. Evidencebased Chinese medicine research $\mathrm{G}$ : prescription patterns of Chinese herbal products for post-surgery colon cancer patients in Taiwan. J Ethnopharmacol. 2014;155(1):702-8

13. Tsai FJ, Ho TJ, Cheng CF, Shiao YT, Chien WK, Chen JH, Liu X, Tsang H, Lin $\mathrm{TH}$, Liao CC, et al. Characteristics of Chinese herbal medicine usage in ischemic heart disease patients among type 2 diabetes and their protection against hydrogen peroxide-mediated apoptosis in H9C2 cardiomyoblasts. Oncotarget. 2017:8(9):15470-89.
14. Tsai FJ, Ho TJ, Cheng CF, Liu X, Tsang H, Lin TH, Liao CC, Huang SM, Li JP, Lin CW, et al. Effect of Chinese herbal medicine on stroke patients with type 2 diabetes. J Ethnopharmacol. 2017;200:31-44.

15. Tsai FJ, Cheng CF, Chen CJ, Lin CY, Wu YF, Li TM, Chuang PH, Wu YC, Lai $\mathrm{CH}$, Liu X, et al. Effects of Chinese herbal medicine therapy on survival and hepatic outcomes in patients with hepatitis $C$ virus infection in Taiwan. Phytomedicine. 2018;57:30-8.

16. Romano PS, Roos LL, Jollis JG. Adapting a clinical comorbidity index for use with ICD-9-CM administrative data: differing perspectives. J Clin Epidemiol. 1993;46(10):1075-9 discussion 1081-1090.

17. Deyo RA, Cherkin DC, Ciol MA. Adapting a clinical comorbidity index for use with ICD-9-CM administrative databases. J Clin Epidemiol. 1992;45(6):613-9.

18. Yang DH, Kang JH, Park YB, Park YJ, Oh HS, Kim SB. Association rule mining and network analysis in oriental medicine. PLoS One. 2013;8(3):e59241.

19. Schuppan D, Ruehl M, Somasundaram R, Hahn EG. Matrix as a modulator of hepatic fibrogenesis. Semin Liver Dis. 2001;21(3):351-72.

20. Benyon RC, Arthur MJ. Extracellular matrix degradation and the role of hepatic stellate cells. Semin Liver Dis. 2001;21(3):373-84.

21. Yoon YJ, Friedman SL, Lee YA. Antifibrotic therapies: where are we now? Semin Liver Dis. 2016;36(1):87-98.

22. Schuppan D, Ashfaq-Khan M, Yang AT, Kim YO. Liver fibrosis: direct antifibrotic agents and targeted therapies. Matrix Biol. 2018;68-69:435-51.

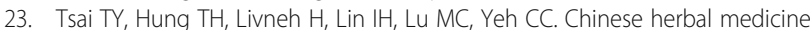
therapy and the risk of mortality for chronic hepatitis B patients with concurrent liver cirrhosis: a nationwide population-based cohort study. Oncotarget. 2018;9(26):18214-23.

24. Tsai TY, Livneh H, Hung TH, Lin IH, Lu MC, Yeh CC. Associations between prescribed Chinese herbal medicine and risk of hepatocellular carcinoma in patients with chronic hepatitis B: a nationwide population-based cohort study. BMJ Open. 2017;7(1):e014571.

25. Liu CY, Chu JY, Chiang JH, Yen HR, Hsu CH. Utilization and prescription patterns of traditional Chinese medicine for patients with hepatitis $C$ in Taiwan: a population-based study. BMC Complement Altern Med. 2016; 16(1):397.

26. Liao YH, Lin CC, Lai HC, Chiang JH, Lin JG, Li TC. Adjunctive traditional Chinese medicine therapy improves survival of liver cancer patients. Liver Int. 2015;35(12):2595-602.

27. Chen FP, Kung YY, Chen YC, Jong MS, Chen TJ, Chen FJ, Hwang SJ. Frequency and pattern of Chinese herbal medicine prescriptions for chronic hepatitis in Taiwan. J Ethnopharmacol. 2008;117(1):84-91.

28. Li JY, Cao HY, Sun L, Sun RF, Wu C, Bian YQ, Dong S, Liu P, Sun MY. Therapeutic mechanism of Yin-Chen-Hao decoction in hepatic diseases. World J Gastroenterol. 2017;23(7):1125-38.

29. Tian X, Liu H, Qiao S, Yin H, Chen M, Hu P, Wang Y, Peng H, Liu F, Pan G, et al. Exploration of the hepatoprotective chemical base of an orally administered herbal formulation (YCHT) in normal and CCl4-intoxicated liver injury rats. Part 2: hepatic disposition in vivo and hepatoprotective activity in vitro. J Ethnopharmacol. 2019;236:161-72

30. Zhang H, Wang X, Hu P, Zhou W, Zhang M, Liu J, Wang Y, Liu P, Luo G. Serum Metabolomic characterization of liver fibrosis in rats and anti-fibrotic effects of Yin-Chen-Hao-Tang. Molecules. 2016;21(1):E126.

31. Yang $Q$, Yang $F$, Tang $X$, Ding $L, X u Y$, Xiong $Y$, Wang Z, Yang $L$. Chlorpromazine-induced perturbations of bile acids and free fatty acids in cholestatic liver injury prevented by the Chinese herbal compound YinChen-Hao-Tang. BMC Complement Altern Med. 2015;15:122.

32. Wang B, Sun MY, Long AH, Cao HY, Ren S, Bian YQ, Lu X, Gu HT, Liu CH, Liu $P$. Yin-Chen-Hao-Tang alleviates biliary obstructive cirrhosis in rats by inhibiting biliary epithelial cell proliferation and activation. Pharmacogn Mag. 2015;11(42):417-25.

33. Lee TY, Chang HH, Lo WC, Lin HC. Alleviation of hepatic oxidative stress by Chinese herbal medicine Yin-Chen-Hao-Tang in obese mice with steatosis. Int J Mol Med. 2010;25(6):837-44

34. Lee TY, Chang HH, Chen JH, Hsueh ML, Kuo JJ. Herb medicine Yin-ChenHao-Tang ameliorates hepatic fibrosis in bile duct ligation rats. J Ethnopharmacol. 2007;109(2):318-24.

35. Han JM, Kim HG, Choi MK, Lee JS, Lee JS, Wang JH, Park HJ, Son SW, Hwang SY, Son CG. Artemisia capillaris extract protects against bile duct ligationinduced liver fibrosis in rats. Exp Toxicol Pathol. 2013;65(6):837-44.

36. Jin H, Sakaida I, Tsuchiya M, Okita K. Herbal medicine Rhei rhizome prevents liver fibrosis in rat liver cirrhosis induced by a choline-deficient L-amino acid-defined diet. Life Sci. 2005;76(24):2805-16. 
37. Yang F, Luo L, Zhu ZD, Zhou X, Wang Y, Xue J, Zhang J, Cai X, Chen ZL, Ma Q, et al. Chlorogenic acid inhibits liver fibrosis by blocking the miR-21-regulated TGFbeta1/Smad7 signaling pathway in vitro and in vivo. Front Pharmacol. 2017;8:929.

38. Mahmoud AM, Hozayen WG, Hasan IH, Shaban E, Bin-Jumah M. Umbelliferone ameliorates CCl4-induced liver fibrosis in rats by Upregulating PPARgamma and attenuating oxidative stress, inflammation, and TGF-beta1/Smad3 signaling. Inflammation. 2019;42:1103.

39. Jung HA, Park JJ, Islam MN, Jin SE, Min BS, Lee JH, Sohn HS, Choi JS. Inhibitory activity of coumarins from Artemisia capillaris against advanced glycation endproduct formation. Arch Pharm Res. 2012;35(6):1021-35.

40. Park JH, Yoon J, Lee KY, Park B. Effects of geniposide on hepatocytes undergoing epithelial-mesenchymal transition in hepatic fibrosis by targeting TGFbeta/Smad and ERK-MAPK signaling pathways. Biochimie. 2015;113:26-34.

41. Kitano A, Saika S, Yamanaka O, Ikeda K, Reinach PS, Nakajima Y, Okada Y, Shirai K, Ohnishi Y. Genipin suppresses subconjunctival fibroblast migration, proliferation and myofibroblast transdifferentiation. Ophthalmic Res. 2006; 38(6):355-60.

42. Algandaby MM. Antifibrotic effects of crocin on thioacetamide-induced liver fibrosis in mice. Saudi J Biol Sci. 2018;25(4):747-54.

43. Zhao XA, Chen G, Liu Y, Wu H, Chen J, Xiong Y, Tian C, Jia B, Wang G, Xia J, et al. Emodin alleviates liver fibrosis of mice by reducing infiltration of Gr1(hi) monocytes. Evid Based Complement Alternat Med. 2018;2018: 5738101.

44. Guo MZ, Li XS, Xu HR, Mei ZC, Shen W, Ye XF. Rhein inhibits liver fibrosis induced by carbon tetrachloride in rats. Acta Pharmacol Sin. 2002;23(8):73944.

45. Lin $Y L$, Wu CF, Huang YT. Phenols from the roots of Rheum palmatum attenuate chemotaxis in rat hepatic stellate cells. Planta Med. 2008;74(10): 1246-52.

46. Wu T, Liu T, Xing L, Ji G. Baicalin and puerarin reverse epithelialmesenchymal transition via the TGF-beta1/Smad3 pathway in vitro. Exp Ther Med. 2018;16(3):1968-74.

47. Li S, Wang Q, Tao Y, Liu C. Swertiamarin attenuates experimental rat hepatic fibrosis by suppressing angiotensin $\mathrm{Il}$-angiotensin type 1 receptorextracellular signal-regulated kinase signaling. J Pharmacol Exp Ther. 2016; 359(2):247-55.

48. Lu CM, Lin LC, Tsai TH. Determination and pharmacokinetic study of gentiopicroside, geniposide, baicalin, and swertiamarin in Chinese herbal formulae after oral administration in rats by LC-MS/MS. Molecules. 2014; 19(12):21560-78.

49. Liang Z, He M, Fong W, Jiang Z, Zhao Z. A comparable, chemical and pharmacological analysis of the traditional Chinese medicinal herbs Oldenlandia diffusa and $\mathrm{O}$. corymbosa and a new valuation of their biological potential. Phytomedicine. 2008;15(4):259-67.

50. Ting $C T$, Kuo $C J$, Hu HY, Lee YL, Tsai TH. Prescription frequency and patterns of Chinese herbal medicine for liver cancer patients in Taiwan: a crosssectional analysis of the National Health Insurance Research Database. BMC Complement Altern Med. 2017;17(1):118.

51. Wu PK. Chi Shing tai W, Liang ZT, Zhao ZZ, Hsiao WL: Oleanolic acid isolated from Oldenlandia diffusa exhibits a unique growth inhibitory effect against ras-transformed fibroblasts. Life Sci. 2009;85(3-4):113-21.

52. Xiang H, Han Y, Zhang Y, Yan W, Xu B, Chu F, Xie T, Jia M, Yan M, Zhao R, et al. A New Oleanolic Acid Derivative against CCI(4)-Induced Hepatic Fibrosis in Rats. Int J Mol Sci. 2017;18:3.

53. Kwon EY, Shin SK, Choi MS. Ursolic Acid Attenuates Hepatic Steatosis, Fibrosis, and Insulin Resistance by Modulating the Circadian Rhythm Pathway in Diet-Induced Obese Mice. Nutrients. 2018;10:11.

54. Gan D, Zhang W, Huang C, Chen J, He W, Wang A, Li B, Zhu X. Ursolic acid ameliorates CCl4-induced liver fibrosis through the NOXs/ROS pathway. J Cell Physiol. 2018;233(10):6799-813.

55. Ma JQ, Ding J, Zhang L, Liu CM. Protective effects of ursolic acid in an experimental model of liver fibrosis through Nrf2/ARE pathway. Clin Res Hepatol Gastroenterol. 2015;39(2):188-97.

56. Wang X, lkejima K, Kon K, Arai K, Aoyama T, Okumura K, Abe W, Sato N, Watanabe S. Ursolic acid ameliorates hepatic fibrosis in the rat by specific induction of apoptosis in hepatic stellate cells. J Hepatol. 2011;55(2):379-87.

\section{Publisher's Note}

Springer Nature remains neutral with regard to jurisdictional claims in published maps and institutional affiliations.

\section{Ready to submit your research? Choose BMC and benefit from}

- fast, convenient online submission

- thorough peer review by experienced researchers in your field

- rapid publication on acceptance

- support for research data, including large and complex data types

- gold Open Access which fosters wider collaboration and increased citations

- maximum visibility for your research: over $100 \mathrm{M}$ website views per year

At BMC, research is always in progress.

Learn more biomedcentral.com/submissions 